\title{
Factors Secreted by Human Neuroblastoma Mediate Doxorubicin Resistance by Activating STAT3 and Inhibiting Apoptosis
}

\author{
Abdelhadi Rebbaa, ${ }^{1,2}$ Pauline M. Chou, ${ }^{1,4}$ and Bernard L. Mirkin ${ }^{1,2,3}$ \\ ${ }^{1}$ Children's Memorial Institute for Education and Research (CMIER), Cancer Biology \\ and Chemotherapy Program \\ ${ }^{2}$ Department of Pediatrics, Northwestern University Medical School, Chicago, Illinois, USA \\ ${ }^{3}$ Department of Molecular Pharmacology and Biological Chemistry, Northwestern University Medical \\ School, Chicago, Illinois, USA \\ ${ }^{4}$ Department of Pathology, Northwestern University Medical School, Chicago, Illinois, USA \\ Accepted January 25, 2001]
}

\begin{abstract}
Background: The transcription factor Stat 3 has been reported to play a key role in protecting cells against apoptosis by up-regulating expression of the anti-apoptotic gene $B c l-x_{L}$. This investigation analyzes the relationship between the development of resistance to doxorubicinmediated apoptosis in neuroblastoma cells (SKN-SH) and activation of the Stat3 signaling pathway.

Materials and Methods: A drug-resistant cell line (SKN-SH/Dox6) was generated by continuous exposure to incremental concentrations of doxorubicin. Specific antibodies were utilized for Western blots and confocal microscopy to determine the nuclear localization of activated Stat3.

Results: Doxorubicin-mediated DNA fragmentation was inhibited and caspase-3 activity decreased in SKN-SH/Dox6 cells. Up-regulation of Stat3 phosphorylation and $\mathrm{Bcl}-\mathrm{x}_{\mathrm{L}}$ expression, increased nuclear translocation of phosphoStat3, and binding to DNA occurred only in resistant
\end{abstract}

SKN-SH/Dox6 cells. The expression of Bcl- $x_{L}$ was inhibited by AG490, an inhibitor of the JAK/Stat 3 signaling pathway, suggesting that the regulation of $\mathrm{Bcl}-\mathrm{x}_{\mathrm{L}}$ and Stat 3 involved a common mechanism. Activation of Stat3 in SKN-SH/Dox6 cells was contingent upon stimulation evoked by ligands secreted by the drug-resistant cells. Evidence to support this hypothesis was provided by experiments in which doxorubicin-sensitive SKN-SH cells were preincubated with conditioned media obtained from doxorubicinresistant SKN-SH/Dox6 cells. This treatment increased Stat 3 activation. It also rendered SKN-SH cells resistant to doxorubicin as demonstrated by a sharp decrease in doxorubicin-induced DNA degradation and cytotoxic potency.

Conclusions: These findings suggest that the resistance of SKN-SH/Dox6 cells to doxorubicin may be mediated by anti-apoptotic factor(s) that are synthesized and secreted by tumor cells in response to cytotoxic agents.

\section{Introduction}

Stats are a family of transcription factors that become activated by phosphorylation in response to extracellular ligands such as cytokines, hormones, or growth factors (1). Upon activation, Stat proteins dimerize and translocate to the nucleus, where they bind to the promoter regions of target genes. The physiologic roles of Stat molecules have been examined by a variety of approaches including the use of knockout mice (2). Animals lacking Stat 3 did not survive beyond early embryogenesis (3), suggesting that this transcription factor is essential for cell survival and organ development.

Recently it has been reported that constitutive activation of Stat 3 inhibits fas-mediated apoptosis and, therefore, contributes to the pathogenesis of

Address correspondence and reprint requests to: Bernard L. Mirkin, PhD, MD, Children's Memorial Institute for Education and Research, 2300 Children's Plaza-Mail Code \# 117, Chicago, IL 60614. Phone: (773) 880-4589; Fax: (773) 880-3282;

E-mail: b-mirkin@northwestern.edu multiple myeloma (4), squamous cell carcinoma (5), and prostate cancer (6). Inhibition of apoptosis by activated Stat 3 was found to be mediated by upregulation of $B c l-x_{L}$ gene expression. The direct relationship between Stat 3 and $B c l-x_{L}$ was demonstrated by in vitro experiments showing the ability of this transcription factor to interact with the $B c l-x_{L}$ gene promoter, causing its up-regulation in myeloma cells (4). Humoral factors that stimulate the gp130/JAK signaling pathway upstream of Stat3, such as interleukin-6, ciliary neurotrophic factor, and leukemia inhibitory factor, can also suppress apoptosis by inducing expression of anti-apoptotic genes of the Bcl2 family (7-10). Pharmacologic inhibition of this signaling pathway with the JAK2 inhibitor, AG490, inhibited Stat 3 activation, decreased expression of the anti-apoptotic gene Bcl-2, and enhanced expression of the pro-apoptotic gene $\operatorname{Bax}(11,12)$. Additional data implicating Stat3 in the protection of tumor cells against apoptosis have been provided by specific targeting of this signaling pathway, using a dominant negative Stat3. Introduction of the dominant negative 
Stat3 in mice led to the inhibition of tumor progression by enhancement of tumor cell apoptosis $(6,13)$.

Treatment of tumor cells with cytotoxic drugs is often associated with increased apoptosis $(14,15)$. Moreover, recent studies have demonstrated that inhibition of apoptosis was associated with drug resistance in different types of malignant tumors (16-18). Accordingly, the role of Stat3 in promoting tumor cell protection against cytotoxic drug-mediated apoptosis and the development of drug resistance has become of critical interest.

The present investigation addresses the putative association between Stat 3 mediated anti-apoptosis and resistance to doxorubicin in human neuroblastoma cells. These findings demonstrate that extracellular secretion of factors synthesized by drug-resistant tumor cells can stimulate Stat 3 signaling and modulate doxorubicin-mediated cytotoxicity.

\section{Material and Methods}

\section{Chemicals and Reagents}

The following items were purchased from the companies cited: Dulbecco's Modified Eagle's Medium (DMEM) and fetal bovine serum (FBS) (BioWhittaker, Walkersville, MD, USA); doxorubicin, 3-(4, 5-dimethyl-2-thiazolyl)2,5-diphenyl tetrazolium bromide (MTT) (Sigma, St. Louis, MO, USA); antibodies to Stat3 and phospho-Stat3 (New England Biolabs, Beverly, MA, USA); antibodies to Bcl-2, Bcl$\mathrm{x}_{\mathrm{L} / \mathrm{S}}$, and NF kappa B (Santa Cruz Biotechnology Inc., Santa Cruz, CA, USA); secondary antibodies conjugated to horseradish peroxidase and enhanced chemiluminescence reagents (ECL) (Amersham, Arlington Heights, IL, USA); immobilon-P transfer membrane for Western blot (Millipore, Bedford, MA, USA); and $\left[\gamma^{32} \mathrm{P}\right]$-ATP $(9.25 \mathrm{Mbq})$ (Dupont NEN, Boston, MA, USA). The oligonucleotide sequence SIE (59-GTG CAT TTC CCG TAA ATC TTG TCT ACA-39) was obtained from Santa Cruz Biotechnology. The T4 polynucleotide kinase was acquired from USB (Cleveland, OH, USA), poly (dIdC), tyrphostin (AG490) from Pharmacia Biotech Inc., Piscatoway, NJ, USA, and the caspase-3-3 colorimetric assay kit from R\&D Systems Inc. (Minneapolis, MN, USA).

\section{Cell Culture, Generation of Doxorubicin Resistant Cells, and Cytotoxicity Assay}

Neuroblastoma (SKN-SH) cells were maintained in DMEM supplemented with $10 \%$ FBS at $378 \mathrm{C}$ in a $5 \% \quad \mathrm{CO}_{2}$ atmosphere. Doxorubicin-resistant cells (SKN-SH/Dox6), were generated by incubating the wild type SKN-SH cells with incremental concentrations of doxorubicin ranging from $10^{29}$ to $10^{26} \mathrm{M}$ over a period of 6 months. Cytotoxic activity of the drug was quantitatively determined by a colorimetric assay utilizing MTT (19). Cells were seeded at $10^{4}$ cells/well in 96-well plates and maintained in culture for $24 \mathrm{hr}$ at $378 \mathrm{C}$ in DMEM supplemented with $10 \%$ FBS. Doxorubicin $\left(10^{29}\right.$ to $\left.10^{26} \mathrm{M}\right)$ was then added to designated wells and the cells incubated for an additional $72 \mathrm{hr}$. MTT ( $10 \mu \mathrm{l}$ of $5 \mathrm{mg} / \mathrm{ml}$ solution) was added to each well and incubated for $4 \mathrm{hr}$ at $378 \mathrm{C}$. The cells were solubilized in $100 \mu \mathrm{l}$ of $\mathrm{HCl} 0.5 \mathrm{~N} /$ isopropanol and incubated for $15 \mathrm{hr}$ at 378C. The optical density of this solution was measured at $570 \mathrm{~nm}$ and cell survival estimated by comparison with untreated control cells.

The effect of conditioned media on the cytotoxic potency of doxorubicin was determined by harvesting media from SKN-SH or SKN-SH/Dox6 cells that had been seeded at $5310^{5} \mathrm{cells} / \mathrm{ml}$ and incubated for $48 \mathrm{hr}$. The media was collected under sterile conditions and transferred to flasks containing $5310^{5}$ cells/ml of the SKN-SH or SKN-SH/ Dox6 cell lines. Following incubation for $48 \mathrm{hr}$, doxorubicin was added at a specific concentration and incubation continued for an additional $48 \mathrm{hr}$, at which time cell number or other parameters were determined.

\section{Detection of Apoptosis}

Apoptosis was assessed either by determination of DNA fragmentation or by measure of caspase-3 activity. Cells were incubated with doxorubicin $(1 \mu \mathrm{M})$ for $24 \mathrm{hr}$ at $378 \mathrm{C}$ and DNA prepared from Triton X-100 lysates for analysis of fragmentation (20). Briefly, cells were lysed in hypotonic solution containing $10 \mathrm{mM}$ Tris $\mathrm{HCl}$ (pH 7.4), $1 \mathrm{mM}$ EDTA, and $0.2 \%$ Triton $\mathrm{X}-100$, and centrifuged at $11,000 \mathrm{~g}$ for 5 min. Supernatants were electrophoresed on a $1 \%$ agarose gel and the DNA fragments visualized by UV light after staining with ethidium bromide.

Caspase- 3 activity was determined in cell extracts after incubation with doxorubicin $(1 \mu \mathrm{M})$ for 24 hr. After washing (twice with PBS), the cells were lysed by addition of $100 \mu$ l of lysis buffer (caspase-3 colorimetric assay kit, R\&D Systems). Caspase-3 activity was assayed by preincubating $50 \mu \mathrm{l}$ of cell lysate containing $200 \mu \mathrm{g}$ of protein in a 96-well plate with $50 \mu \mathrm{l}$ of 23 reaction buffer and $5 \mu \mathrm{l}$ of caspase- 3 substrate (DEVD-pNA) for $2 \mathrm{hr}$ at $378 \mathrm{C}$. Optical density was determined at $405 \mathrm{~nm}$ using an ELISA plate reader.

\section{Western Blot Analysis}

The cells were seeded in $25 \mathrm{~cm}^{2}$ flasks containing DMEM supplemented with $10 \%$ FBS and incubated at $378 \mathrm{C}$. After $48 \mathrm{hr}$ of incubation, the cells were washed with cold PBS, and the monolayer was solubilized by the addition of $200 \mu \mathrm{l}$ of lysis buffer (50 mM HEPES pH 7.4, $150 \mathrm{mM} \mathrm{NaCl}, 100 \mathrm{mM}$ NaF, $1 \mathrm{mM} \mathrm{MgCl} 2,1.5 \mathrm{mM}$ EGTA, $10 \%$ glycerol, $1 \%$ Triton X100, $1 \mu \mathrm{g} / \mathrm{ml}$ leupeptin, and $1 \mathrm{mM}$ phenylmethyl sulfonyl fluoride). Insoluble material was removed by centrifugation and the protein concentration of the supernatant determined. The soluble protein fraction $(50 \mu \mathrm{g})$ was electrophoresed on SDS-PAGE and transferred to an Immobilon-P 
membrane. Stat3, Phospho-Stat3, NF kappa B, and $\mathrm{Bcl}-\mathrm{x}$ proteins were identified by incubation of the membrane with specific antibodies. Complexes were detected by sequential blotting with biotinylated secondary antibodies linked to peroxidase and reactive bands identified by ECL.

\section{Preparation of Nuclear and Cytoplasmic Protein Fractions}

Nuclear extracts were prepared from SKN-SH and SKN-SH/Dox6 cells following a previously described procedure $(21)$. Cells grown in $75 \mathrm{~cm}^{2}$ flasks were scraped into $10 \mathrm{ml}$ tris-buffered saline (TBS) and pelleted by centrifugation ( $1500 \mathrm{~g}$ for $5 \mathrm{~min}$ ). After a second wash with TBS, the pellet was re-suspended in $400 \mu \mathrm{l}$ of buffer A (10 mM HEPES pH 7.9; $10 \mathrm{mM} \mathrm{KCl}$; $0.1 \mathrm{mM}$ EDTA; $0.1 \mathrm{mM}$ EGTA; $1 \mathrm{mM}$ DTT; $0.5 \mathrm{mM}$ PMSF). The mixture was incubated for $30 \mathrm{~min}$ on ice, then $25 \mu \mathrm{l}$ of a $10 \%$ solution of Nonidet NP-40 was added and the homogenate centrifuged for $30 \mathrm{sec}$. The nuclear pellet was resuspended in $50 \mu \mathrm{l}$ of ice cold buffer B (20 mM HEPES pH 7.9; 0.4 M NaCl; 1 mM EDTA; 1 mM EGTA; 1 mM dithiothreitol; $1 \mathrm{mM}$ PMSF). The samples were then rocked at $48 \mathrm{C}$ for $30 \mathrm{~min}$. Following centrifugation (12000 g for $5 \mathrm{~min}$ ), protein concentration was determined in the supernatant and samples stored at $2708 \mathrm{C}$ for Western blot or DNA gel shift assay.

\section{DNA Gel Shift Assay}

SIE oligonucleotides were radiolabeled with $\left[{ }^{32} \mathrm{P}\right]-$ ATP using T4 polynucleotide kinase as described previously (21). The radiolabeled sequence was then purified by passage through a Nuc-Trap Probe column (Stratagene, La Jolla, CA, USA). Radiolabeled SIE $(50,000 \mathrm{cpm})$ was incubated with $5 \mu \mathrm{g}$ of nuclear protein in the presence of $2 \mu \mathrm{g}$ poly (dI-dC) for $30 \mathrm{~min}$ at room temperature in a total volume of $20 \mu \mathrm{l}$, containing $10 \mathrm{mM}$ HEPES $\mathrm{pH} 7.9,50 \mathrm{mM}$ $\mathrm{KCl}, 1 \mathrm{mM}$ EDTA, $5 \mathrm{mM} \mathrm{MgCl}, 10 \%$ (v/v) glycerol, and $5 \mathrm{mM}$ dithiothreitol. The samples were resolved by electrophoresis using a $5 \%$ polyacrylamide gel. The gel was dried and radioactive bands detected by autoradiography.

\section{Confocal Microscopy}

Cellular localization of phospho-Stat 3 was determined by confocal microscopy. Cells were seeded onto sterile glass slides and incubated for $24 \mathrm{hr}$ in DMEM containing $10 \%$ FBS. The media was aspirated, the cells washed with PBS, and then fixed with PBS containing 3\% paraformaldehyde for $10 \mathrm{~min}$ at $48 \mathrm{C}$. Nonspecific sites were blocked by incubating slides in TBS-0.1\% Tween 20 buffer (TBST) containing 5.5\% Normal Goat Serum for $1 \mathrm{hr}$ at room temperature. The cells were then incubated with anti-phospho-Stat 3 for $24 \mathrm{hr}$ at $4^{\circ} \mathrm{C}$. After washing with TBST, the cells were incubated with FITC-labeled anti-rabbit (1/500) in TBST for an additional $45 \mathrm{~min}$ and localization of phospho-Stat 3 visualized by confocal microscopy.

\section{Statistical Analyses}

A two-sided paired $t$-test was used to determine statistical significance. $p$ values for all comparisons are presented in the text (significance is set at $p, 0.05$ ).

\section{Results}

Characterization of Doxorubicin-Induced Cell Death in SKN-SH and SKN-SH/Dox6 Human Neuroblastoma Cells

The data shown in Figure 1A demonstrated that SKN-SH/Dox6 cells were much less sensitive to doxorubicin-mediated cell death $\left(\mathrm{IC}_{50}\right.$ of 6.43 $10^{25} \mathrm{M}$ ) than the wild-type SKN-SH cells $\left(\mathrm{IC}_{50}\right.$ of $\left.4310^{27} \mathrm{M}\right)$. The MTT assay used to quantify cell death in this cellular model does not, however,
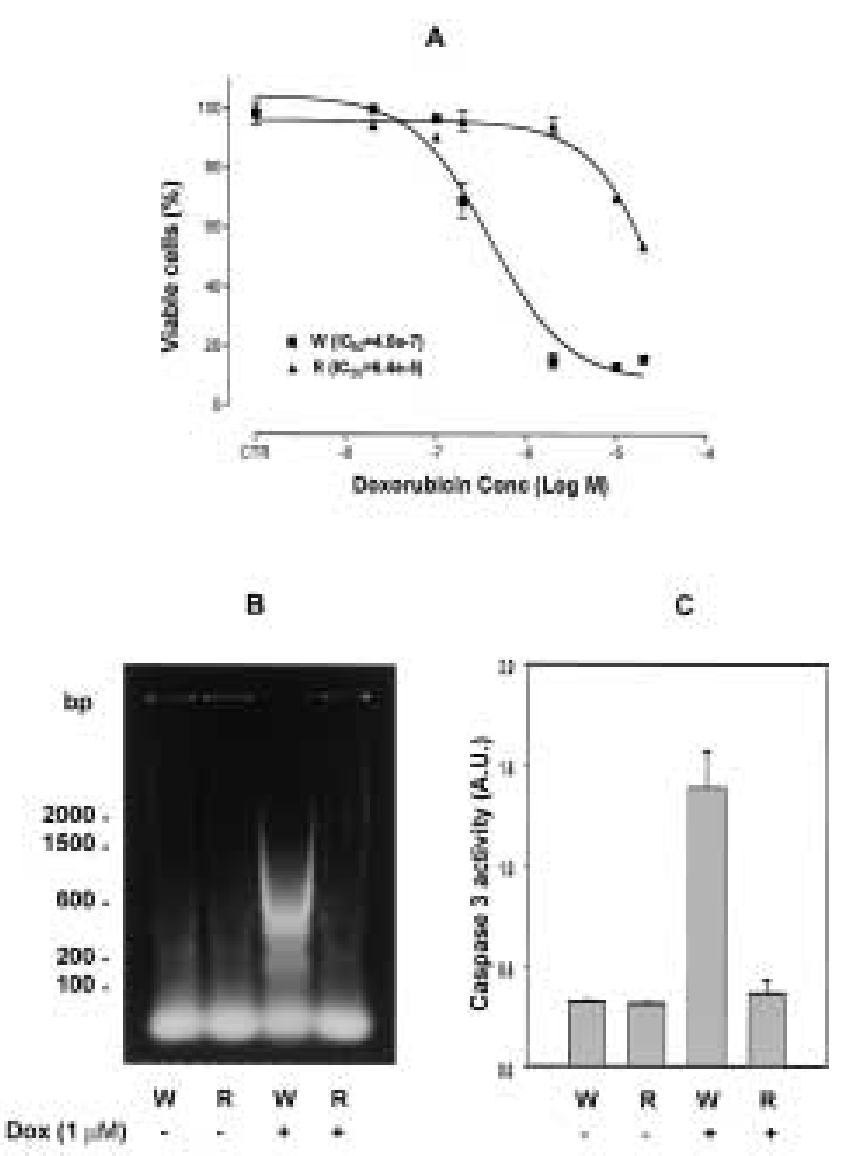

Fig. 1. Differential effects of doxorubicin on SKN-SH wild-type (W) and SKN-SH/Dox6 drug-resistant (R) human neuroblastoma cells. (A) Cytotoxic response of $\mathrm{W}$ and $\mathrm{R}$ cells to doxorubicin. Cells were incubated with doxorubicin for $72 \mathrm{hr}$, after which cell viability was determined by the MTT assay. (B) DNA degradation following incubation of $\mathrm{W}$ and $\mathrm{R}$ cells with doxorubicin $(1 \mu \mathrm{M})$ for $24 \mathrm{hr}$. Equal amounts of DNA were electrophoresed on $1 \%$ agarose gel. DNA fragments were stained with ethidium bromide and visualized under UV light. (C) Caspase-3 activity in $\mathrm{W}$ and $\mathrm{R}$ cells. Cells were treated with doxorubicin (1 $\mu \mathrm{M})$ for $24 \mathrm{hr}$ and caspase-3 activity assayed in the cell lysate. Note that caspase- 3 activity correlates with DNA degradation shown in Panel B. Data are expressed in arbitrary units (AU) and represent the mean 6 SEM of triplicate determinations. 
provide information about the cellular mechanism that mediates doxorubicin cytotoxicity.

Because many cytotoxic drugs, including doxorubicin, exert their cytotoxic action by inducing apoptotic cell death $(22,23)$ the role of doxorubicinmediated apoptosis as a molecular mechanism for drug toxicity was investigated in this model. Doxorubicin $(1 \mu \mathrm{M})$ induced DNA fragmentation in wild-type SKN-SH cells (Fig. 1B); in contrast, similar treatment did not affect DNA integrity in drug-resistant SKN-SH/Dox6 cells. The activity of caspase-3, a key mediator in the apoptotic signaling cascade (24), was also suppressed in SKN-SH/Dox6 cells when compared to SKN-SH cells, following incubation with doxorubicin (Fig. 1C). These data suggest that alterations in anti-apoptotic signaling pathways may be responsible for the decreased susceptibility of SKN-SH/Dox6 cells to doxorubicininduced apoptosis.

\section{Stat3 Activation in SKN-SH and SKN-SH/Dox6 Human Neuroblastoma Cells}

The expression of Stat 3 and its activation were compared in SKN-SH and SKN-SH/Dox6 cells to determine their correlation with the development of drug resistance in these cells.

Western blot analyses demonstrated the presence of Stat3 in both SKN-SH and SKN-SH/Dox6 cell lines. The expression of this transcription factor in both the cytoplasmic and nuclear fractions of SKN-SH/Dox6 cells was slightly greater than that of SKN-SH cells (Fig. 2A). In contrast, phospho-Stat3 was strongly expressed in the nuclei of SKNSH/Dox6 cells $(p, 0.03)$, and almost absent in SKN-SH cells (Fig. 2A and 2B). Expression of NFkappa B, which served as an internal control, did not differ between the two cell lines.
A

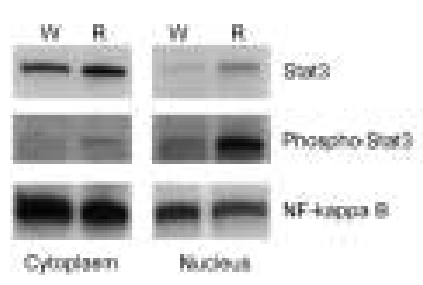

B

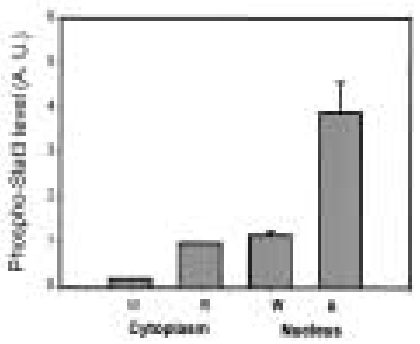

Fig. 2. Expression and phosphorylation of Stat3 in SKN-SH wild-type (W) and SKN-SH/Dox6 drug-resistant (R) human neuroblastoma cells. (A) Western blot of Stat3, phospho-Stat3, and NF-kappa B in the cytoplasm and nucleus of $\mathrm{W}$ and R cells. Cytoplasmic and nuclear fractions were prepared as described in "Methods." Proteins were electrophoresed on SDS-PAGE and probed with specific antibodies to Stat3, phospho-Stat3, and NF-Kappa B. (B) Densitometric analysis of Phospho-Stat3 expression in the cytoplasm and nuclei of $\mathrm{W}$ and $\mathrm{R}$ cells (Sigma Gel Program). Data represent the mean 6 SEM of three independent experiments expressed in arbitrary units (AU).
It is of interest that phospho-Stat3 was barely detectable in the cytoplasmic fraction of SKNSH/Dox6 cells, indicating that the activated transcription factor had translocated to the nucleus. Because tyrosine phosphorylation of Stat3 in SKNSH/Dox6 cells occurred in the absence of any experimentally induced extracellular stimulus, such as the addition of cytokines, hormones, or growth factors, these findings suggest that Stat 3 was constitutively activated in SKN-SH/Dox6 cells.

\section{Nuclear Translocation and Binding of Phospho-Stat 3 to DNA}

The nuclear localization of phospho-Stat 3 was determined by confocal microscopy (Fig. 3A). SKN-SH cells had a diffuse staining pattern localized mainly to the cytoplasm with virtually no nuclear localization. In contrast, doxorubicin-resistant cells displayed
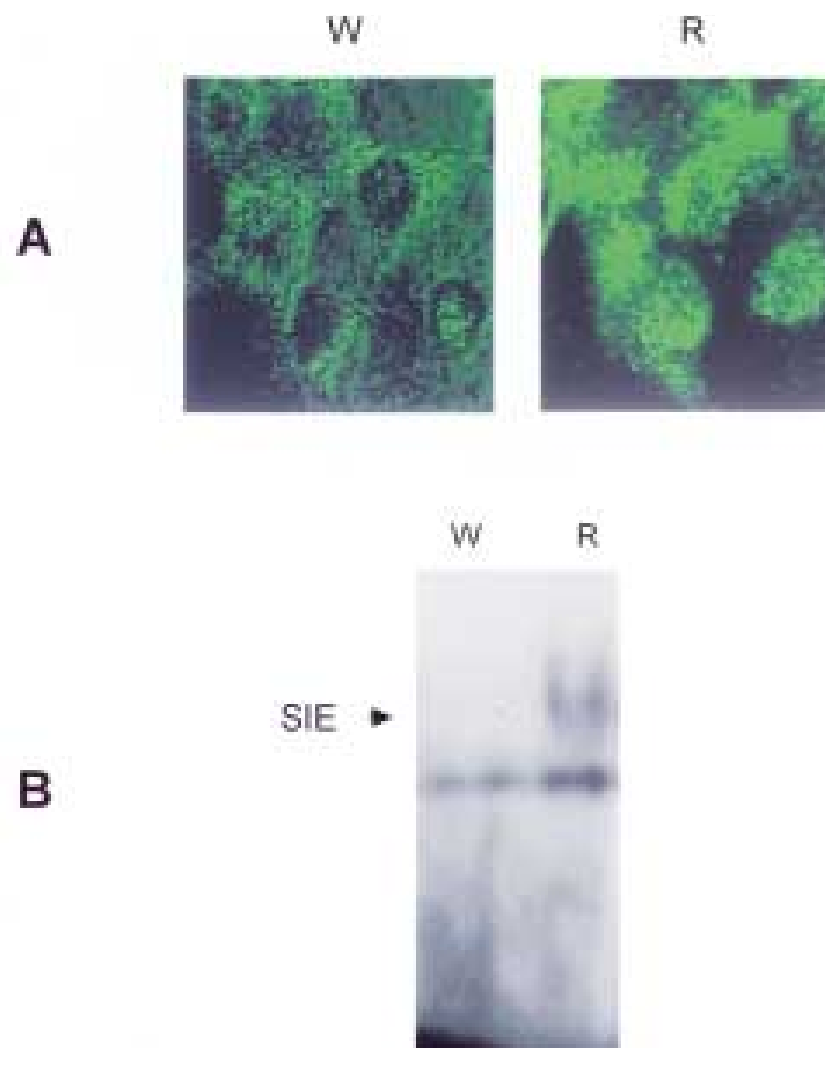

Fig. 3. Cellular localization and binding of phospho-Stat3 to DNA in SKN-SH wild-type (W) and SKN-SH/Dox6 doxorubicin-resistant (R) human neuroblastoma cells. (A) Confocal microphotographs showing differences in expression of phospho-Stat3 between $\mathrm{W}$ and $\mathrm{R}$ cell lines. Note increased nuclear localization of phospho-Stat 3 in $\mathrm{R}$ cells when compared to W cells. Cells were plated on a sterile slide, cultured for 2 days, and stained with anti-phospho-Stat 3 and FITC-conjugated secondary antibody, as described in "Methods." (B) DNA mobility gel shift analysis of phospho-Stat 3 binding to sis-inducible element (SIE). Nuclear proteins were extracted and incubated with radiolabeled DNA. Protein-DNA complexes (SIE) and free SIE were separated on 5\% SDS-PAGE and autoradiographs prepared. 
intense staining, which was mainly located in the nucleus. These morphologic data confirm the constitutive phosphorylation of Stat3 mentioned above (see Fig. 2), and demonstrate the translocation of phospho-Stat 3 from its cytoplasmic site of interaction with a cellular kinase, to the nucleus of SKNSH/Dox6 cells.

The binding of phospho-Stat3 to DNA was determined by DNA gel shift analysis, using a radiolabeled DNA sequence (sis-inducible element [SIE]) known to interact with the phospho-Stat3 homodimer and phospho-Stat3/Stat 1 heterodimer $(25,26)$. Binding to SIE was observed only in the SKNSH/Dox6 cells (Fig. 3B). Western blot analyses with anti-Stat 1 and anti-Stat 2 antibodies had demonstrated their lack of expression in either SKN-SH or SKN-SH/Dox6 cell lines (data not shown). Collectively, these findings suggest that the Stat3 homodimer may be the principal component of the SIE complex formed in SKN-SH/Dox6 cells. These data also indicate that constitutively phosphorylated Stat 3 appears to be functional in terms of its ability to translocate, bind to DNA, and potentially activate specific genes in the nucleus.

\section{Expression of Bcl-2 and Bcl- $x_{L}$ in SKN-SH} and SKN-SH/Dox6 Human Neuroblastoma Cells

Stat 3 activation and increased expression of genes of the Bcl-2 family were investigated to determine their relationship to decreased apoptosis in drug-resistant

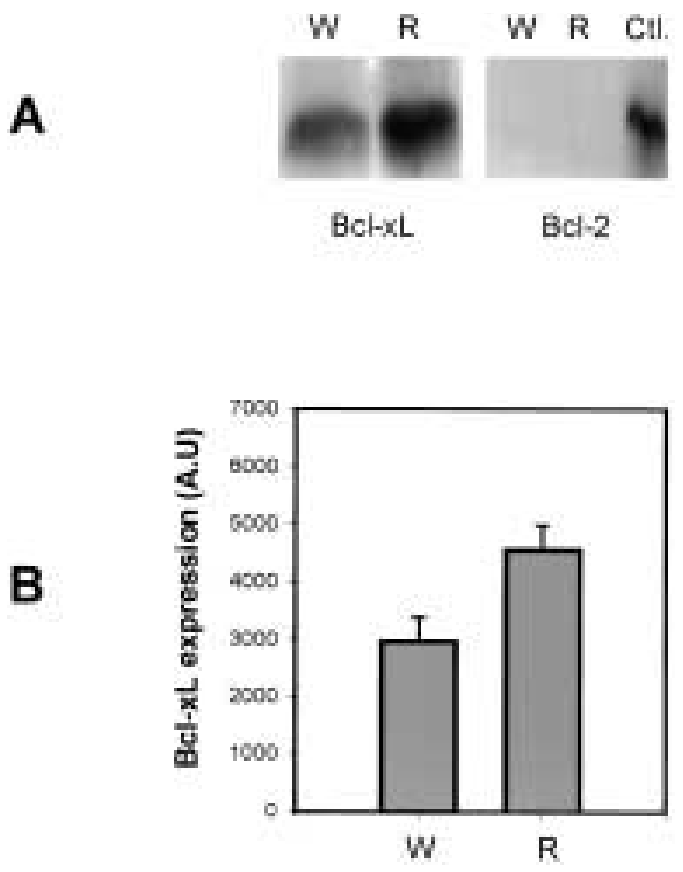

Fig. 4. Bcl-2 and Bcl- $x_{\mathrm{L}}$ expression in SKN-SH wild-type (W) and SKN-SH/Dox6 doxorubicin-resistant (R) cells. (A) Bcl- $\mathrm{x}_{\mathrm{L}}$ and $\mathrm{Bcl}-2$ expression in $\mathrm{W}$ and $\mathrm{R}$ cells. (B) Densitometric analysis of $\mathrm{Bcl}-\mathrm{x}_{\mathrm{L}}$ expression in $\mathrm{W}$ and $\mathrm{R}$ cell lines. $\mathrm{R}$ significantly greater than $\mathrm{W}(p, 0.01)$. Data represent mean 6 SEM of four independent experiments. cells. As previously described, this relationship has been demonstrated in the case of resistance to fasmediated apoptosis $(4,11,27)$. Western blot analyses performed to detect $\mathrm{Bcl}-2$ revealed that this molecule was not expressed in either the SKN-SH or SKNSH/Dox6 cell lines (Fig. 4A). Although Bcl- $\mathrm{x}_{\mathrm{L}}$ was present in both cell lines, it was significantly increased $(p, 0.01)$ in SKN-SH/Dox6 cells when compared to SKN-SH cells (Fig. 4A,B). These data provide further support for a causal relationship between Stat 3 activation and up-regulation of $\mathrm{Bcl}-\mathrm{x}_{\mathrm{L}}$ expression as events associated with the inhibition of apoptosis.

\section{Inhibition of the JAK/Stat Signaling by Tyrphostin (AG490): Effects on Stat3 Activation and Bcl- $x_{L}$ Expression}

Further analysis of the putative association between activation of Stat 3 and expression of $\mathrm{Bcl}-\mathrm{x}_{\mathrm{L}}$ was investigated using the JAK antagonist, tyrophostin AG490 (Fig. 5). Incubation of SKN-SH and SKNSH/Dox6 cells with AG490 (10 $\mu \mathrm{M})$ decreased the nuclear concentration of Stat 3 (Fig. 5A) and of phospho-Stat3 (Fig. 5B) to a greater extent in the wild-type SKN-SH than drug-resistant SKN-SH/ Dox 6 cells. Bcl- $\mathrm{x}_{\mathrm{L}}$ expression was also inhibited and expression of the pro-apoptotic gene $B c l-x_{s}$ slightly enhanced, particularly in the wild-type SKN-SH cells (Fig. 5C). These findings provide additional support for the interrelationship between $B c l-x_{L}$ gene expression and Stat3 phosphorylation. They also suggest that activation of this pathway is JAK dependent.

A

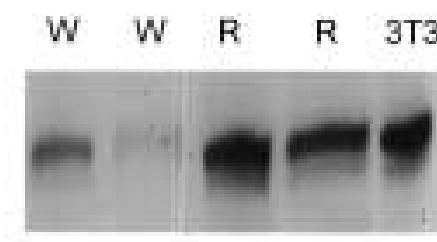

Stat3

B

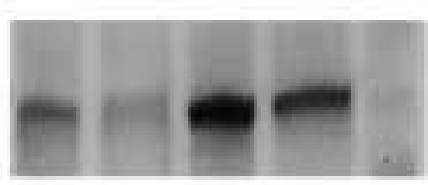

Phospho-Stat3

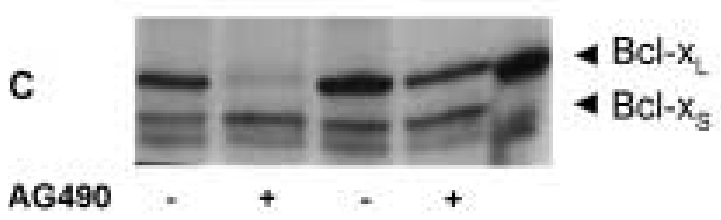

Fig. 5. Effect of tyrphostin (AG490) on Stat3 activation and Bcl- $x_{L}$ expression in SKN-SH wild-type (W) and SKNSH/Dox6 doxorubicin-resistant $(R)$ human neuroblastoma cells. W and R cells were treated with AG490 (10 $\mu \mathrm{M})$ for $15 \mathrm{hr}$. The nuclear localization of Stat3 (A) and phospho-Stat3 (B) was determined by Western blot. Expression of Bcl- $\mathrm{x}_{\mathrm{L}}$, and $\mathrm{Bcl}-\mathrm{x}_{\mathrm{S}}(\mathbf{C})$ was determined in whole cell lysates using an antibody that recognized the same epitope on both molecules. $3 \mathrm{~T} 3$ represents protein cell extract from $3 \mathrm{~T} 3$ cells that served as control for expression of Stat3 and Bcl- $\mathrm{x}_{\mathrm{L}}$. 

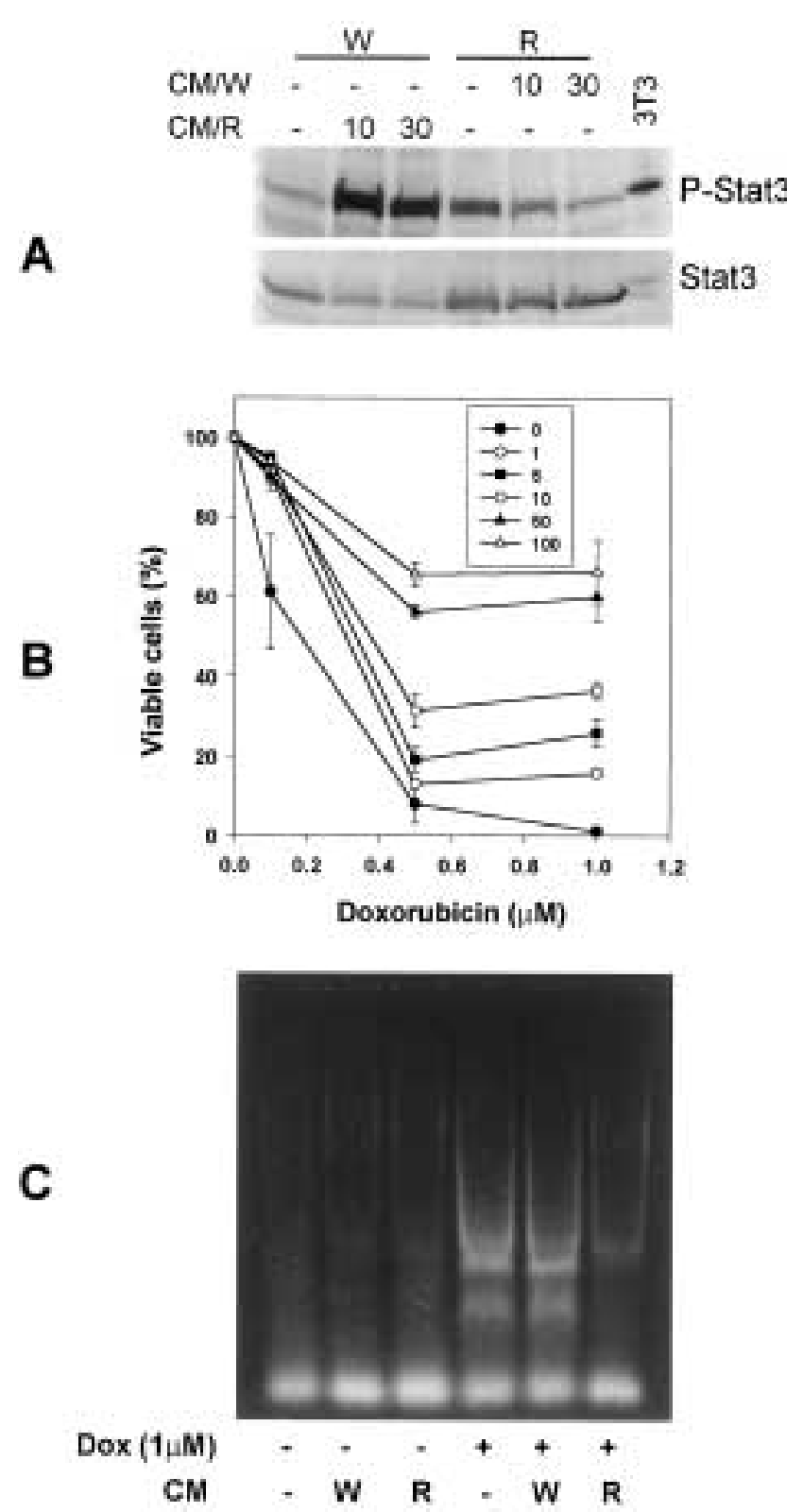

Fig. 6. Response of SKN-SH wild-type cells (W) to incubation with conditioned media (CM) from doxorubicin-resistant cells (R): Effect on Stat3 phosphorylation, cytotoxic response to doxorubicin, and susceptibility to doxorubicin-induced apoptosis. (A) Effect on Stat3 phosphorylation: $\mathrm{W}$ and $\mathrm{R}$ cells were incubated with conditioned media obtained from $\mathrm{R}$ and $\mathrm{W}$ cells, respectively, for 10 or $30 \mathrm{~min}$. Phosphorylation of Stat 3 was determined by Western blot using anti-phosphoStat3 antibody. (B) Effect on cell response to doxorubicin: $\mathrm{W}$ cells were preincubated for $48 \mathrm{hr}$ with increasing volumes $(0-100 \mu \mathrm{l})$ of conditioned media from $\mathrm{R}$ cells. The $\mathrm{W}$ cells were then incubated with varying concentrations of doxorubicin for $72 \mathrm{hr}$, and viable cells determined by the MTT assay. (C) Effect of conditioned media on doxorubicin-induced DNA degradation in W cells: $\mathrm{W}$ cells were incubated with conditioned media from $\mathrm{W}$ or $\mathrm{R}$ cells for $48 \mathrm{hr}$ prior to an additional $24 \mathrm{hr}$ of incubation with doxorubicin $(1 \mu \mathrm{M})$. DNA was extracted and electrophoresed on a $1 \%$ agarose gel.
Modulation of Stat3 Phosphorylation, Doxorubicin

Resistance, and Apoptosis by Cellular Secretion of Humoral Factors

Demonstration that Stat3 was constitutively activated in SKN-SH/Dox6 cells led to the concept that molecules synthesized and secreted by drugresistant cells were putative determinants of this process. This hypothesis was tested by adding conditioned media from drug-resistant SKN-SH/Dox6 cells to wild-type SKN-SH cells for 10 and $30 \mathrm{~min}$ at room temperature to determine its effect on Stat 3 phosphorylation. At both time periods, phosphoStat3 was markedly up-regulated in wild-type SKNSH cells (Fig. 6A). In contrast, conditioned media from SKN-SH cells did not increase Stat3 phosphorylation in drug-resistant SKN-SH/Dox6 cells (Fig. 6A), but was associated with a time-dependent decrease. This probably reflects the action of phosphatases on phosphorylated Stat3. A 48-hr incubation of wild-type SKN-SH cells with varying volumes of conditioned media from SKN-SH/Dox6 cells caused a concentration-dependent decrease in the cytotoxic effect of doxorubicin (Fig. 6B) and inhibition of doxorubicin-induced DNA fragmentation (Fig. 6C). These data suggest that ligand(s) secreted into the media by SKN-SH/Dox6 cells can initiate Stat 3 activation, suppression of doxorubicininduced toxicity and inhibition of apoptosis.

\section{Discussion}

The development of resistance to cytotoxic agents represents an adaptive biological response by neuroectodermal tumors that leads to complex and vexing therapeutic outcomes. Many cellular mechanisms causing drug resistance have been described and these involve alterations in membrane transport, drug metabolism, and substrate and enzyme amplification, to cite but a few (28). In addition, tumor cells may also express alterations in the processes that regulate apoptotic cell death $(16,29)$. Therefore, identification of the molecules and mechanisms that modulate apoptosis and define their role in tumor cell adaptation to cytotoxic drugs may be potentially useful for the development of innovative therapeutic strategies.

In this study, we investigated alterations in the Stat $3 / \mathrm{Bcl}-\mathrm{x}_{\mathrm{L}}$ anti-apoptotic pathway in relation to doxorubicin-mediated apoptosis and expression of drug resistance in SKN-SH human neuroblastoma cells. The doxorubicin-resistant cell line (SKNSH/Dox6) generated for this purpose displayed a sharp decrease in doxorubicin-induced cytotoxicity that was almost 100 times lesser than the parental cells (Fig. 1A). Susceptibility of SKN-SH/Dox6 cells to drug-mediated apoptosis was also reduced as evidenced by inhibition of doxorubicin-mediated DNA degradation (Fig. 1B) and caspase-3 activity (Fig. 1C).

The pattern of Stat3 signaling differed significantly between wild-type and drug-resistant cells. 
Although the overall expression of Stat3 was slightly increased in the cytoplasm of SKN-SH/Dox6 cells (Fig. 2), phospho-Stat3 expression was markedly elevated, particularly in the nuclei of these cells. Confocal microscopy and DNA gel shift assays confirmed the nuclear localization of phospho-Stat3 (Fig. 3) and provided additional evidence for the activation of this transcription factor in drug-resistant cells. Activation of Stat3 was constitutively regulated in SKN-SH/Dox6 cells, because no exogenous stimulus (e.g., addition of ligands) was required to elicit this response. Therefore, the possibility that molecular factors responsible for Stat 3 activation are constitutively expressed in drug-resistant cells cannot be excluded.

To further define the putative relationship between constitutive activation of Stat 3 and resistance to doxorubicin in human neuroblastoma cells, expression of downstream gene targets of the Bcl-2 family were investigated. Western blot analyses revealed that Bcl-2 was absent in both SKN-SH and SKN-SH/Dox6 cells (Fig. 4); however, the expression of Bcl- $\mathrm{x}_{\mathrm{L}}$ was significantly elevated in the resistant cell line, SKN-SH/Dox6. This finding, in addition to the inhibition of both Stat 3 activation and expression of Bcl- $x_{L}$ by the JAK2 inhibitor AG490 (Fig. 5), indicates that these two signaling molecules are components of a common anti-apoptotic pathway activated in doxorubicin-resistant human neuroblastoma cells.

The potential mechanism(s) by which Stat 3 became constitutively activated in drug-resistant human neuroblastoma cells was also investigated. We hypothesized that this cascade might be initiated by extracellular ligands (cytokines, hormones, or growth factors) secreted by drug-resistant cells into the culture media. Incubation of wild-type SKN-SH cells with conditioned medium obtained from doxorubicinresistant SKN-SH/Dox6 cells strongly activated Stat 3 and inhibited doxorubicin-stimulated toxicity in these cells (Fig. 6A,B). Doxorubicin-mediated DNA degradation in SKN-SH cells was also prevented by this treatment (Fig. 6C). We propose that constitutive activation of Stat3, observed in SKNSH/Dox6 cells, may be modulated by an autocrine loop initiated by the secretion of stimulatory ligands from drug-resistant cells. The nature of these antiapoptotic stimuli has not yet been determined and is currently under active investigation in our laboratory.

The role of Stat 3 in preventing doxorubicininduced toxicity has been recently investigated in myocardial tissue (30). Targeted overexpression of Stat 3 in the mouse heart provided protection against doxorubicin-mediated cardiomyopathy, and improved survival rate by preventing the progression of cardiac failure. Our data are in agreement with these findings and indicate that in addition to its protective role against short-term treatment with doxorubicin, constitutive activation of Stat 3 may be considered as a mediator of cellular adaptation to the sustained administration of doxorubicin. In terms of therapeutic strategies, these findings collectively suggest that targeted anti-Stat 3 therapy at the tumor site or Stat3 overexpression in drug sensitive organs, such as the heart, may constitute a valuable adjuvant in the treatment of drug-resistant tumors and attenuation of organ-specific drug toxicity.

In conclusion, the major findings of our investigation suggest that resistance to doxorubicin in the human neuroblastoma cell line, SKN-SH, is associated with decreased apoptosis and constitutive activation of the Stat $3 / \mathrm{Bcl}-\mathrm{x}_{\mathrm{L}}$ signaling pathway. Stimulation of this anti-apoptotic pathway appeared to be elicited by factor(s) secreted only from drugresistant cells. These data also introduce the concept that production of anti-apoptotic molecules by drugresistant cells may represent an alternative mechanism underlying tumor cell adaptation to cytotoxic drugs and the development of drug resistance.

\section{Acknowledgments}

The authors wish to thank Ms. Sandra Clark for her excellent technical assistance and Ms. Roberta Gerard for expert editorial oversight. Support for this investigation was provided by the following organizations: John W. Anderson Foundation (B.L.M.), Medical Research Institute Council (B.L.M.), Coleman/Fannie May Foundation (B.L.M.), and Illinois Department of Public Aid (P.M.C.A.R.).

\section{References}

1. Darnell JE Jr. (1997) Stats and gene regulation. Science 277: 1630-1635.

2. Akira S. (1999) Functional roles of Stat family proteins: lessons from knockout mice. Stem Cells 17: 138-146.

3. Takeda K, Noguchi K, Shi W, et al. (1997) Targeted disruption of the mouse Stat 3 gene leads to early embryonic lethality. Proc. Natl. Acad. Sci. U.S.A. 94: 3801-3804.

4. Catlett-Falcone R, Landowski TH, Oshiro MM, et al. (1999) Constitutive activation of Stat 3 signaling confers resistance to apoptosis in human U266 myeloma cells. Immunity 10: 105-115.

5. Grandis JR, Drenning SD, Zeng Q, et al. (2000) Constitutive activation of Stat 3 signaling abrogates apoptosis in squamous cell carcinogenesis in vivo. Proc. Natl. Acad. Sci. U.S.A. 97: 4227-4232.

6. Ni Z, Lou W, Leman ES, Gao AC. (2000) Inhibition of constitutively activated Stat 3 signaling pathway suppresses growth of prostate cancer cells. Cancer Res. 60: 1225-1228.

7. Schwarze MM, Hawley RG. (1995) Prevention of myeloma cell apoptosis by ectopic bcl-2 expression or interleukin 6-mediated upregulation of bcl-xL. Cancer Res. 55: 22622265.

8. Peters R, Levraz S, Perey L. (1998) Apoptotic regulation in primitive hematopoietic precursors. Blood 92: 2041-2052.

9. Fujio Y, Kunisada K, Hirota H, Yamaguchi-Takihara K, Kishimoto T. (1997) Signals through gp 130 upregulate bcl-x gene expression via STATl binding cis-element in cardiac myocytes. J. Clin. Invest. 99: 2898-2905.

10. Tolosano E, Cutufia MA, Hirsch E, et al. (1996) Ciliary neurotrophic factor constitutively expressed in the nervous system of transgenic mice protects embryonic dorsal root ganglion neurons from apoptosis. Eur. J. Neurosci. 8: 52 1-529. 
11. Zushi S, Shinomura Y, Kiyohara T, et al. (1998) Stat3 mediates the survival signal in oncogenic ras-transfected intestinal epithelial cells. Int. J. Cancer 78: 326-330.

12. Nielsen M, Kaestel CG, Eriksen KW, et al. (1999) Inhibition of constitutively activated Stat3 correlates with altered Bcl2/Bax expression and induction of apoptosis in mycosis fungoides tumor cells. Leukemia 13: 735-738.

13. Niu G, Heller R, Catlett-Falcone R, et al. (1999) Gene therapy with dominant-negative Stat3 suppresses growth of the murine melanoma B16 tumor in vivo. Cancer Res. 59: 5059-5063.

14. Schmitt E, Sane AT, Steyaert A, Cimoli G, Bertrand R. (1997) The Bcl-xL and Bax-alpha control points: modulation of apoptosis induced by cancer chemotherapy and relation to TPCK-sensitive protease and caspase activation. Biochem. Cell Biol. 75: 301-314.

15. Schmitt CA, Lowe SW. (1999) Apoptosis and therapy. $J$. Pathol. 187: 127-137.

16. Zunino F, Perego P, Pilotti S, Pratesi G, Supino R, Arcamone F. (1997) Role of apoptotic response in cellular resistance to cytotoxic agents. Pharmacol. Ther. 76: 177-185.

17. Liu R, Page C, Beidler DR, Wicha MS, Nunez G. (1999) Overexpression of $\mathrm{Bcl}-\mathrm{x}(\mathrm{L})$ promotes chemotherapy resistance of mammary tumors in a syngeneic mouse model. Am. J. Pathol. 155: $1861-1867$.

18. Dalton WS, Jove R. (1999) Drug resistance in multiple myeloma: approaches to circumvention. Semin. Oncol. 26: 23-27.

19. Rebbaa A, Chou PM, Vucic I, Mirkin BL, Tomita T, Bremer EG. (1999) Expression of bisecting GlcNAc in pediatric brain tumors and its association with tumor cell response to vinblastine. Clin. Cancer Res. 5: 3661-3668.

20. Uckun FM, Waddick KG, Mahajan S, et al. (1996) BTK as a mediator of radiation-induced apoptosis in DT-40 lymphoma B cells. Science 273: 1096-1100.
21. Schreiber E, Matthias P, Muller MM, Schaffner W. (1989) Rapid detection of octamer binding proteins with 'miniextracts', prepared from a small number of cells. Nucleic Acids Res. 17: 6419.

22. Friesen C, Fulda S, Debatin KM. (1999) Cytotoxic drugs and the CD95 pathway. Leukemia 13: 1854-1858.

23. Muller I, Niethammer D, Bruchelt G. (1998) Anthracyclinederived chemotherapeutics in apoptosis and free radical cytotoxicity (Review). Int. J. Mol. Med. 1: 491-494.

24. Porter AG, Janicke RU. (1999) Emerging roles of caspase-3 in apoptosis. Cell Death Differ. 6: 99-104.

25. Bhat GJ, Thekkumkara TJ, Thomas WG, Conrad KM, Baker KM. (1995) Activation of the Stat pathway by angiotensin II in T3CHO/ATlA cells. Cross-talk between angiotensin II and interleukin-6 nuclear signaling. J. Biol. Chem. 270: 1905919065.

26. Zhong Z, Wen Z, Darnell JE Jr. (1994) Stat3: a STAT family member activated by tyrosine phosphorylation in response to epidermal growth factor and interleukin-6. Science 264: 95-98.

27. Catlett-Falcone R, Dalton WS, Jove R. (1999) STAT proteins as novel targets for cancer therapy. Signal transducer an activation of transcription. Curr. Opin. Oncol. 11: 490-496.

28. Biedler JL. (1994) Drug resistance: genotype versus phenotype-thirty-second G. H. A. Clowes Memorial Award Lecture. Cancer Res. 54: 666-678.

29. Kojima H, Endo K, Moriyama H, et al. (1998) Abrogation of mitochondrial cytochrome c release and caspase- 3 activation in acquired multidrug resistance. J. Biol. Chem. 273: 16647-16650.

30. Kunisada K, Negoro S, Tone E, et al. (2000) Signal transducer and activator of transcription 3 in the heart transduces not only a hypertrophic signal but a protective signal against doxorubicin-induced cardiomyopathy. Proc. Natl. Acad. Sci. U.S.A. 97: 315-319. 